\title{
Equipping graduates for the 21st century workplace: what IT competencies matters most to stakeholders
}

\section{Dr. Tanya Stanko P.E., Innopolis University}

Tanya Stanko is a Vice-Provost of Education at Innopolis University. She specializes in launching new Universities from scratch, including setting up curricula and polices, recruiting faculty and students. She holds $\mathrm{PhD}$ in Computational Aeroacoustics from the University of Leeds and worked as researcher at Technical University of Munich. Her current research interests include investigation of the professional competencies, gender diversity in engineering, relations between universities, industry and government.

Mrs. Oksana Zhirosh, Unium 


\title{
Equipping graduates for the 21st century workplace: what IT competencies matters most to stakeholders
}

\begin{abstract}
IT University Innopolis is a newly established IT university in Kazan, Russia, with the mission to foster innovation in order to address critical scientific, technological and innovation challenges and gaps facing Russia and the world IT industry. The education system is designed to foster in its graduates qualities that are needed in the modern, rapidly changing world. The University proposed a comprehensive framework of competencies to be developed in its graduates.
\end{abstract}

As a reference framework for competencies we used $\mathrm{ABET}^{1}$, CDIO Syllabus ${ }^{3}$, and results of the recent study ${ }^{6}$ conducted among stakeholders including those in Russia. Here we intend to understand how different stakeholders at different stages of their life and career perceive the relative importance of competencies. In order to answer this question we have conducted an extensive online survey including three groups of stakeholders: highschool pupils intending to study IT, undergraduate students pursuing a degree in IT, and professionals working in IT. By high-school pupils intending to study IT we mean those who attend extra-curriculum classes outside school, thus demonstrating special interest in IT, and reported their wish to pursue a degree in IT in future. A supplementary education company Unium provided this data. The results show consistent replies among the groups that participated in the online survey and some discrepancy with the feedback from stakeholders interviewed in the previous study, namely top management stakeholders, who placed a stronger emphasis on disciplinary knowledge, team work and communication skills, than did employers, students and high-school pupils respondents.

The results of this study will be used to educate students about the expectations of the employers regarding their competencies, to tailor the university courses, and to implement soft-skills components in the supplementary STEM courses for high-school students.

\section{Background}

The society of the 21 st century experiences a rapid transition to the age of information. This new model requires human resources of a new kind - trained professionals able to use knowledge and technology in the most efficient manner. New challenges brought by developing technologies demand increased knowledge and non-traditional ways of thinking, and education that helps to address varied and complex problems.

According to a study done at Oregon State University $(2006)^{10}$, competencies represent knowledge and skills required for performing and supporting business processes. At the same time they serve as the basis for creating value in an organization. Other researchers state that competency is "the ability to meet individual or social demands successfully, or to carry out an activity or task. Each competence is built on a combination of interrelated cognitive and practical skills, knowledge (including tacit knowledge), motivation, value orientation, attitudes, emotions, and other social and behavioral components that together can be mobilized for effective action",

Modern society in general needs to be more competent than it was in the previous decades when means of processing information were traditional and did not imply total automation. Some researchers argue that training techniques or literacy of individuals in multiple languages and codes that information employs (textual, iconic, hypertextual, 
audiovisual, multimedia, etc.), should be a recurring, continuing goal throughout the education system as a whole, from primary education to higher education ${ }^{2}$.

In addition, international organizations have focused their attention both on the development of advanced curricula and instruction in general. This has been reflected in several projects supported by UNESCO and OECD. One such project, called "DeSeCo" (Determination and Selection of Competencies), had published a number of research papers in the 2000s which lay a theoretical foundation for the new understanding of the concept of competencies in education and in the IT industry ${ }^{5,12,13}$.

In the 1960s, when modern computer science degrees originated in their current form, competencies as a reference for education were formulated in the area of vocational or occupational training, closely linked to the processes of in-company training and technological training in educational institutions. However, over the years, most traits of competencies have been incorporated into the institutions that train professionals; this practice is much more inclusive, and not limited to the technical area ${ }^{3}$. Besides promoting the development of certain attributes (skills, knowledge, attitudes, aptitudes and values), it was felt that the design of training should consider the need to intervene within the context and the culture of the workplace. At the same time, it should allow for training in specific contexts to be generalizable ${ }^{7}$.

Innopolis University ${ }^{9}$ has identified a set of key competencies necessary for graduates in IT specialties. These competencies are in agreement with the IT competencies used by the International Accreditation Board for Engineering and Technology ${ }^{1}$ and reflect the opinion of the stakeholders in Russia and abroad ${ }^{6.8}$. The list of competencies is presented in Appendix I.

\section{Methodology}

In the earlier study ${ }^{6}$ we interviewed top managers of IT companies, government officials, and prominent academicians in order to understand what competencies are most important for University graduates to demonstrate in order to be successful. In this study we have conducted an online survey among high-school pupils interested in entering IT careers, students of IT specialties, and IT professionals. Figure 1 shows the diagram of groups of stakeholders involved in the survey.

The respondents were asked to grade the importance of IT competencies on the scale: 1 Not Important, 2 - Moderately Important, 3 - Important, 4 - Highly Important, 5 Essential.

In addition to the online anonymous survey we conducted a set of interviews with selected representatives from each group.

The questionnaire has been split into three blocks:

1. Information about current occupation and work experience

2. Grading IT competencies

3. Information on gender, age group, country of birth, country of study, and country of current occupation

Respondents were not allowed to start grading IT competencies before answering questions in section 1 , however they were allowed to omit section 3 . Therefore data on age group and geographical details is lacking for $6.4 \%$ of responses. 
In total we received over 1600 responses. 980 were complete questionnaires, i.e. sections 1,2 are complete and section 3 partially completed. We filtered out obviously fake responses. 980 responses include 68 from high-school pupils, 178 from students, 696 from professionals without international experience, and 38 from professionals with international experience.

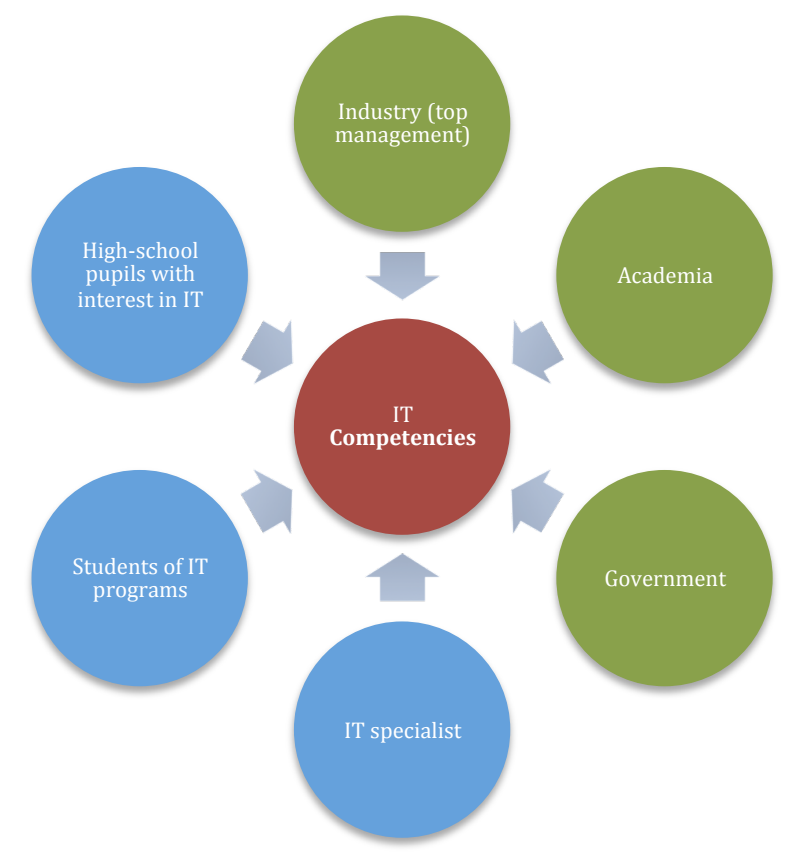

Figure 1. Diagram of stakeholders involved in the study. Legend: green - participant of earlier study ${ }^{6}$, blue - participants of the current study.

\section{How critical are the respondents?}

Here we report mean grades of IT competencies by stakeholders. Therefore it is important to understand how critical the respondents are in their judgment. Figure 2 represents distribution of the grades in percentage of overall grades.

Overall $1 \%$ of responses were 1 - Not Important, $6 \%$ were 2 - Moderately Important, $19 \% 3$ - Important, 35\% 4 - Highly Important, and 39\% 5 - Essential.

\section{Age distribution of the respondents.}

Figure 3 shows the distribution of the respondents by age group. This graph covers those respondents who specified their age group $-93 \%$ of the total respondents. Here we see that the most active group of the respondents corresponds to the age of 23-26 years old young IT professionals. Very likely this reflects the presence of the group in the online professional communities that we have used to advertise our survey.

\section{Results}

Figure 1 Appendix II illustrates the main result of the survey - the relative importance of IT competencies perceived by different groups of stakeholders. Here we present the results, together with the data obtained in the earlier study ${ }^{6}$, in which we interviewed the following groups of stakeholders: senior representatives from academia, top management from the industry, and senior representatives of government from Russia, EU and USA. 


\section{Grades used by respondents in \% of total number}

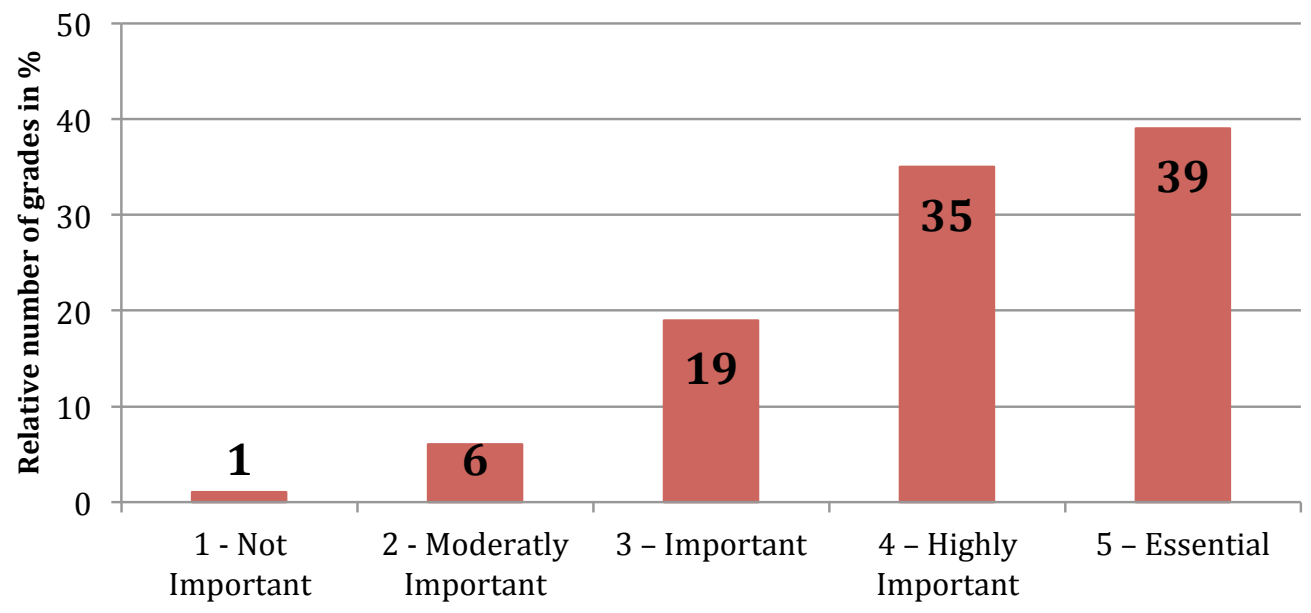

Figure 2. Distribution of the responses as a percentage of the total number of responses.

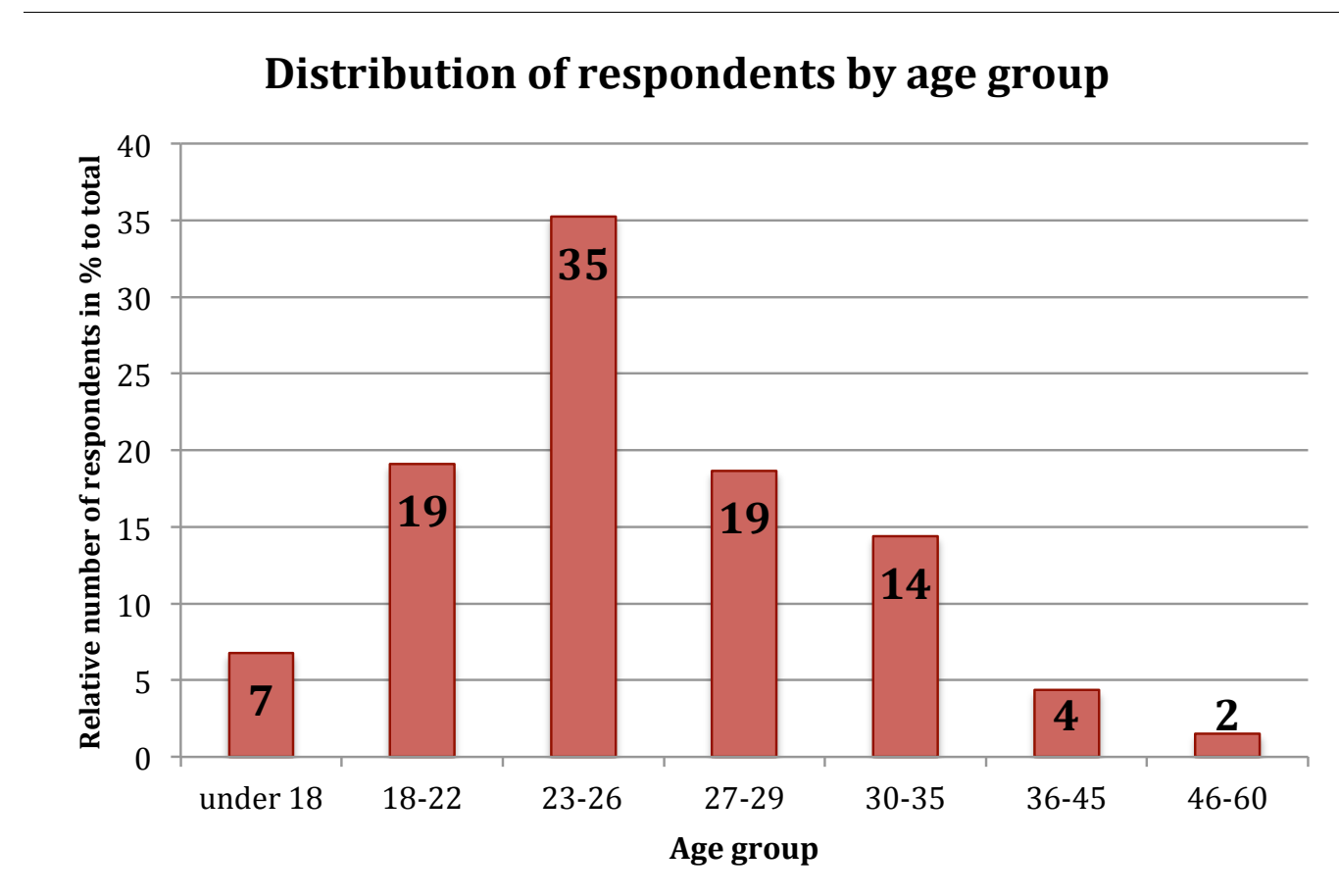

Figure 3. Distribution of the respondents by age group

All respondents of our current survey were born in Russia or the former USSR. Therefore we have decided to allocate professionals with international experience - those who lived and/or studied abroad - as a separate category. We anticipated that their perception of the importance of IT competencies could be different from those who have spent all their life so far in Russia.

During this survey we found that most students of IT specialties and some of high-school children have part-time jobs in IT. It should be mentioned here that students in Russia, in general, are financially independent from their parents. Students receive living allowances from the Russian government, and have additional income from part-time jobs. Therefore we have decided to merge students and IT specialists in one category. 
Even though many high-school pupils have part-time jobs in IT too, they remain financially dependent on parents and therefore we decided to keep them as a separate group.

The results are presented with statistical error bars.

In general, all competencies presented in the survey have been valued as important - this is an optimistic result, demonstrating that stakeholders share professional values.

More specifically we see that Disciplinary knowledge is highly valued by senior representatives from industry, academia, and government, and somewhat less valued by other categories. It was observed that IT specialists tend to attach less value to the knowledge of fundamental disciplines, while top managers put significant stress on this competence. High-school pupils are closest to the opinion of senior stakeholders (within error-bar limits), see first set bars on Figure 1 in Appendix.

Here are some quotes from the interviews:

"It is useful to take a fresh look, and nobody denies the possibility of creating a new algorithm. A good example would be how recently a 12-year-old student found vulnerability in the NSA security system, therefore an uncluttered mind which is actually not overloaded with a great amount of maths, physics and other sciences can come up with a higher quality algorithm than a person who possesses all that knowledge"

"I believe that the main skill is having structured reasoning. That's the first thing. Secondly, a person should have broad knowledge of mathematics because all programming is practically based on maths to this or that extent. The main quality of a programmer is being able to come up with new algorithms instead of looking for the already existing ones, in other words, when it comes to programmes that nobody has written before you this is when programming turns from purely technical into creative activity and it is necessary to create something new, to bring something new into this world, so to say"

The knowledge of tools at the same time is slightly more appreciated by IT specialists than by senior stakeholders, though the difference rate is within the statistical error.

An illustration of the importance of tools - what do high-school children say about skills they need to be successful IT specialists?

... to know programming languages ...

... to know HTML ...

... to be experienced ...

... to have experience with making sites ...

... to have opportunity to work with experts in order to learn from them ...

Another interesting observation is that the Communication and Teamwork skills are not seen equally important by senior management and IT employers. There is a stronger emphasis on communications with machines/computers than with humans:

"This [the importance of programmer's job] was described very well by Kurt Vonnegut in his "Utopia 14", or "Player Piano" where all the people and human functions were replaced by machines and machine tools, and I believe that future probably belongs to those people who are capable of managing these machines" 
It was expected that specialists with international experience would demonstrate more coherence with senior stakeholders in attaching importance to communication and interpersonal communications, but that was not the case. We detected only a slight increase in the importance those with international experience attach to communication and teamwork. This finding might be related to the small pool of respondents working abroad.

We were surprised to discover that Innovation and Creative thinking skill is rated rather low by Russian IT specialists working abroad. This fact requires further investigation.

It is inspiring to see that high-school pupils in general demonstrate coherence of opinions with senior stakeholders - this means that government and other senior managers deliver a clear message to young people.

\section{Women in IT - Where have all the girls gone?}

An interesting result of the current survey relates to the presence of women of different age groups in IT. In total we have received $10 \%$ of responses from women. Figure 4 illustrates the distribution of women in IT by age group.

Here we see that more than $30 \%$ of responses from women are from high-school girls who have an interest in IT. (By interest we mean that girls attend additional informatics and programming classes after school.) These extracurricular activities usually require extra fees, which implies that girls' interest in IT is supported by their parents.

\section{Percent of women in IT by agegroup}

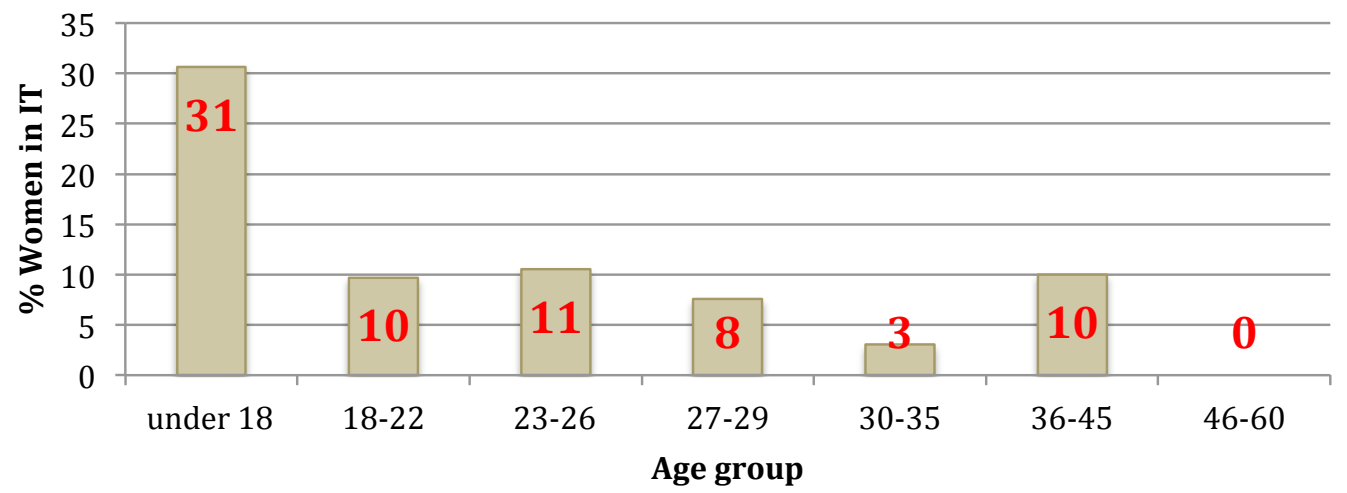

Figure 4. Distribution of women in IT by age group.

The relative number of girls drops dramatically at the University level. Only $10 \%$ of women entering university intend to pursue degrees in IT and this fraction remains constant from that point on, i.e., $10 \%$ of women graduates receive degrees in IT and $10 \%$ of women graduates in the workforce work in IT professions. The only drop in this fraction is a temporary one between the ages of 30-35, might be related to maternity leave, not effectively handled by employers. The absence of women in the age group of over 45 years may be attributed to the fact that IT profession is relative young. But where have the $2 / 3$ of girls gone on the edge of entering University? This is a very interesting observation which requires additional study as it represents a huge loss of potential IT specialists. 


\section{Geographical migration of IT specialists}

Many respondents provided data on their place of birth, place of study and current place of work. We created maps of migration of IT specialists in the world and inside Russia.

All the respondents who participated in the survey were born within the borders of the former USSR, see Figure 5. Their place of the currant occupation varies and we observe that around $3.9 \%$ of respondents emigrated beyond the borders of the former USSR, see Figure 6 . This corresponds to the official statistics of migration abroad $-3.6 \%$ in the period of $1991-2007^{11}$.

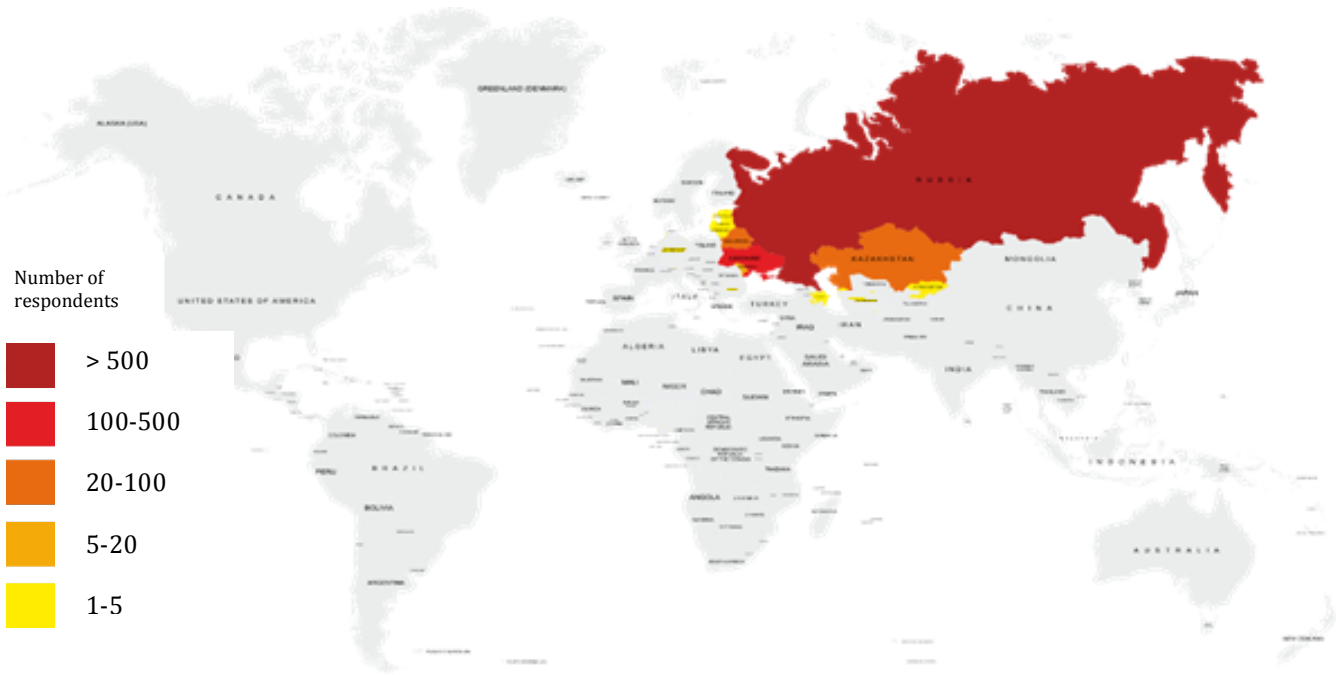

Figure 5. Current world map of the respondents' place of birth by country (all within former USSR boarders)

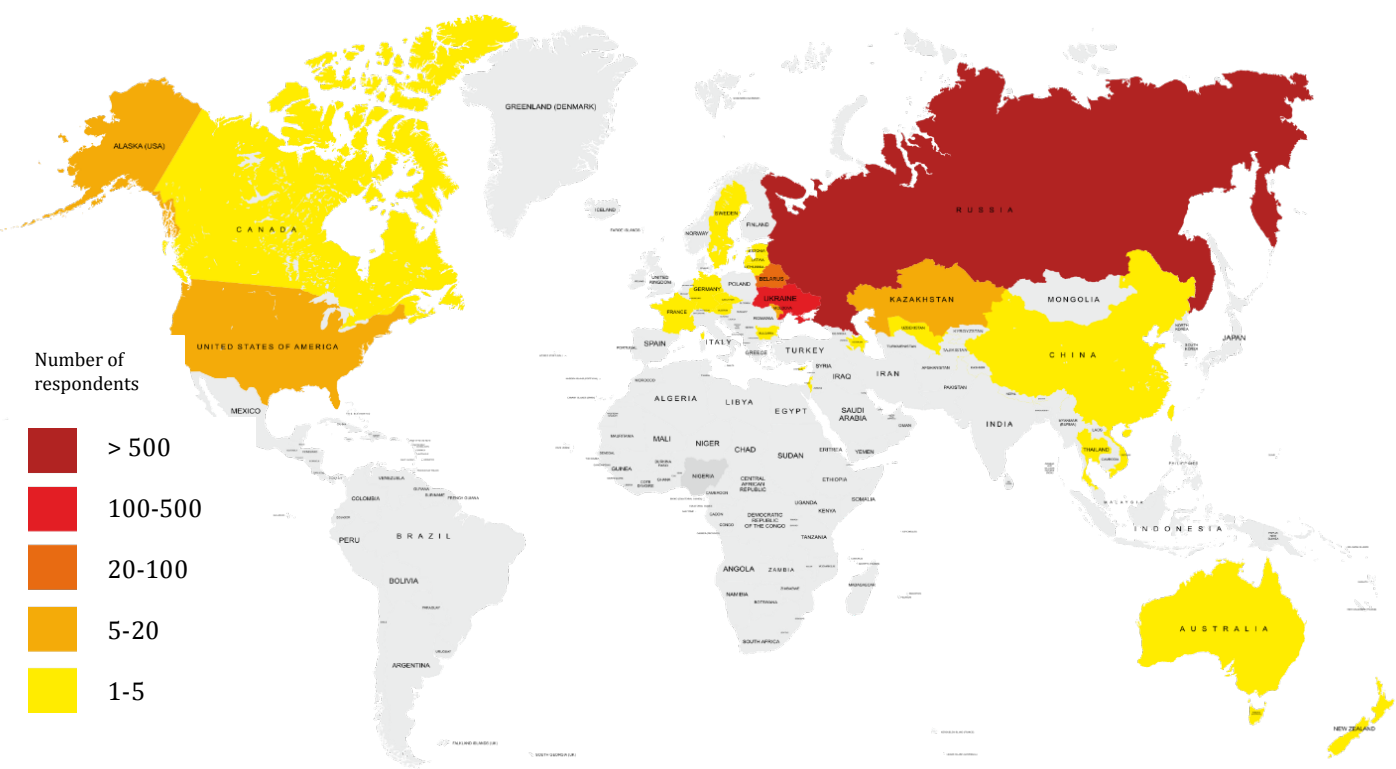

Figure 6. Current world map of the respondents' place of occupation by country 


\section{Conclusions and plans for future research}

In this study we have demonstrated that the IT competencies chosen by Innopolis University are highly valued by a large scope of stakeholders: from high-school pupils to senior managers and government officials.

Our current study is a unique research highlighting opinions of large groups of stakeholders in Russia. We have observed that the opinion of Russian IT professionals is statistically close to their EU and US colleagues with some minor discrepancies in how they rate the importance of communication skills, innovation and teamwork.

We have discovered that $2 / 3$ of girls showing interest in IT profession do not pursue degrees in IT. This is an important lost source of potential IT professionals and we plan to investigate its causes in future studies.

The research results demonstrate that high-school children want to learn more about a wide range of IT tools and principles of programming. IT courses for high-school children in different educational institutions should provide exposure to various IT fields (animation, design, modelling, programming etc.), in order to give this group a better understanding of IT jobs and also of what their colleagues do, which will result in higher productivity. Extracurriculuar IT courses for school children should pay proper attention to developing their communication and team-work skills. Such educational courses should aim to attract more girls to IT industry.

We have also demonstrated that there is a migration of IT specialists within Russia: professionals move to more economically developed central European regions in Russia. This corresponds to migration patterns of the overall workforce in Russia.

We would like to conduct similar online surveys involving IT professionals in EU, Asia and the US in order to understand if there are culturally determined differences in the perception of the relative importance of IT competencies by different national groups.

Acknowledgments.

The authors are grateful to "Unium" - a supplementary education company in Russia which provides courses for school children in 15 subjects, including mathematics and computer science, for technical support in organizing an online survey, access to their school children and trainers teaching IT subjects.

\section{References}

1. ABET Educational outcomes: Criteria for Accrediting Computing Programs, 2012 - 2013. [online] Available at: http://www.abet.org/DisplayTemplates/DocsHandbook.aspx?id=3142 [Accessed 26 Jan 2013]

2. Area, Manuel (2010). "Why Offer Information and Digital Competency Training in Higher Education?". Information and Digital Competencies in Higher Education, Revista de Universidad y Sociedad del Conocimiento (RUSC). Vol. 7, No 2.

3. CDIO Syllabus v2.0, An Updated Statement of Goals for Engineering Education, [online] Available at: http://www.cdio.org/framework-benefits/cdio-syllabus [Accessed 26 Jan 2013]

4. De Pablos, Juan (2010). "Higher Education and the Knowledge Society. Information and Digital Competencies", Information and Digital Competencies in Higher Education, Revista de Universidad y Sociedad del Conocimiento (RUSC). Vol. 7, No 2.

5. EAEA General Assembly (2003), "Definition and Selection of Competencies: Theoretical and Conceptual Foundations (DeSeCo): Strategy Paper on Key Competencies - An overarching frame of reverence for an assessment and research program ", [online] Available at:

http://www.google.com/url? sa=t\&rct=j\&q=\&esrc=s\&source=web\&cd=1\&ved=0CCsQFjAA\&url $=$ http $\% 3 \mathrm{~A} \% 2 \mathrm{~F} \% 2 \mathrm{Fwww}$.eaea.org $\% 2 \mathrm{FGA} \% 2 \mathrm{~F} 11 \mathrm{~g}$.doc\&ei=SNjGUp7zOYi6oQTq5YGgDg\&usg= AFQjCNHo6N4I8Jf05Yxj24a19ZbTTlt8dg\&sig2=GOcUlUe- 
8X3X6C8d39bZpQ\&bvm=bv.58187178,d.cGU [Accessed 26 Jan 2013]

6. Edström, K, Crawley, E. F., and Stanko, T (2013). "Educating Engineers for Research-based Innovation - Creating the learning outcomes framework", Proceedings of the 9th International CDIO Conference, Massachusetts Institute of Technology and Harvard University School of Engineering and Applied Sciences, Cambridge, Massachusetts, June 9 - 13, 2013.

7. Gonscy, A. (1996). "Instrumentation-based education competencies. Theoretical perspectives and practices in Australia”. In: A. Argüelles (comp.). Competencias laborales y educación basadas en normas de competencia. Mexico: Limusa

8. iCarnegie Global Report on Stakeholde's analysis of IT industry in Russia, July 2013 - internal document.

9. Kondratiev, D., Tormasov, A., Stanko, T., Jones, R., Taran, G.(2013). "Innopolis University - a new IT resource for Russia",Proceedings of the International Conference on Interactive Collaborative Learning (ICL), Kazan, Russa, September 25 - 27, 2013.

10. Oregon State University, "Defining Competencies" (2006), [online] Available at: http://www.ous.edu/sites/default/files/dept/hr/files/defining_comp.pdf [Accessed 26 Jan 2013]

11. Palnikov, M. (2007), "Forth wave of immigration" (in Russian). [online] Available at: http://www.perspektivy.info/srez/val/chetvertaja_volna emigracii 2007-12-22.htm [Accessed 26 Jan 2013]

12. Rychen, D., Salganic, L. (2003). "Key competencies for a successful life and a well-functioning society", DeSeCo.

13. Rychen, D. (2006). "Competencias clave: cómo afrontar los desafíos importantes de la vida", DeSeCo. 
Appendix I

\section{Competency Domains}

\section{MATH \& SCIENCE FUNDAMENTALS}

1. DISCIPLINARY KNOWLEDGE

- Apply knowledge of computing and math appropriate to the discipline

- Apply algorithmic principles and computing theory in modeling and design of computer-based systems

- Knowledge of applied science in mathematics, software engineering, and information systems

2. EXPERIMENTATION

- Analyze problems

- Identify and define appropriate computing requirements

- Design, diagnosis, and debug

- Conduct experiments to validate predictions

\section{TECHNICAL ACUMEN}

3. TOOLS

- Use contemporary tools and techniques for computing practice

- Understanding of modern system design and analysis tools to build computing and information systems and solve problems

- Use of program-specific tools appropriate to the domain and context

4. SYSTEMS THINKING

Broad understanding of the impact of solutions within the following contexts:

- Organization \& Industry

- Professional

- Ethical

- Legal

- Security

- Social

5. PROBLEM SOLVING AND CRITICAL THINKING

- Analyze and solve a range of computing problems

- Analyze local and global impact of complex problems

- Manage uncertainty and unknowns in decision making
6. SYSTEM DESIGN / SW ENG

- Ability to design, implement, and evaluate a system, component, or program to meet desired needs

- Ability to design, implement, and evaluated a system, component, or program that considers tradeoffs and constraints

- Apply design and development principles in the construction of software systems of varying complexity

\section{PROFESSIONAL / INDUSTRY SKILLS}

7. COMMUNICATION

- Interpersonal communication

- Communicating in English in technical, business, and social context (English as a tool)

- Written communication

- Oral communication and presentation skills

- Communicating within a professional context

8. TEAMS

- Team leadership and stewardship/followership

- Manage team dynamics/conflict

- Multi-disciplinary and inter-cultural teams

- Project management and coordination

\section{INNOVATION AND LIFE SKILLS}

9. LIFELONG LEARNING

- Metacognition

- Reflection and self-assessment

- Information and media literacy

- Professional development

10. INNOVATION / CREATIVE THINKING

- New and novel solutions to problems

- Risk-taking in decision-making

- Use of unorthodox/non-traditional techniques 
Appendix II
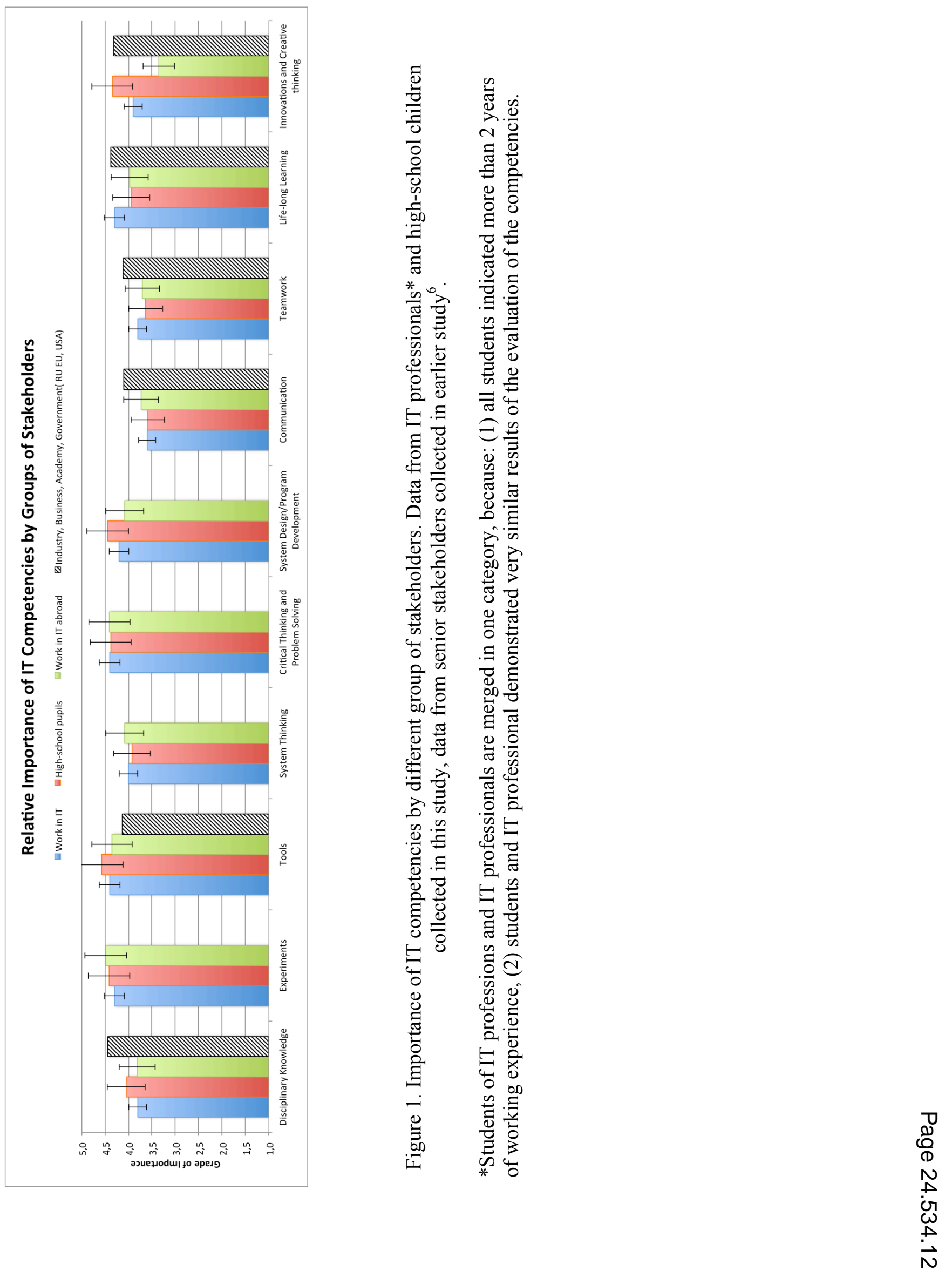